\title{
Optimization of flow control devices in a ten- strand billet caster tundish
}

\author{
*Shu-guo Zheng and Miao-yong Zhu \\ School of Metallurgy, Northeastern University, Shenyang 110819, China
}

\begin{abstract}
The physical model of a ten-strand billet caster tundish was established to study the effects of various flow control devices on the melt flow. Before and after the optimization of the melt flow, the inclusion removal in the tundish was evaluated by plant trials. The physical modeling results show that when combined with a baffle, the turbulence inhibitor, instead of the impact pad, can significantly improve the melt flow. A turbulence inhibitor with a longer length of inner cavity and without an extending lip at the top of the sidewall seems to be efficient in the improvement of the melt flow. Various types and designs of baffles all influence the flow characteristics significantly. The "V" type baffles are better than the straight baffles for flow control. The "V" type baffle with four inclined holes at the sidewall away from the stopper rods is better in melt flow control than the one with one inclined hole at each sidewall. The combination of a well-designed turbulence inhibitor and an appropriate baffle shows high efficiency on improving the melt flow and an optimal proposal was presented. Plant trials indicate that, compared with the original tundish configuration in prototype, the inclusions reduce by $42 \%$ and the inclusion distribution of individual strands is more similar with the optimal one. The optimal tundish configuration effectively improves the melt flow in the ten-strand billet caster tundish.
\end{abstract}

Key words: billet continuous casting; ten-strand caster tundish; flow control device; physical modeling; plant trials
CLC numbers: TP391.9
Document code: A
Article ID: 1672-6421(2016)06-414-08

I

$n$ the continuous casting of steel, the tundish is used as an intermediate vessel placed between the ladle and the mould, receiving the molten steel from the ladle and distributing it to the moulds. In addition to its role as a distribution vessel, the tundish is also used as a reactor to produce clean steel and assure smooth operation. For a conventional continuous casting process to produce steel blooms or billets, a tundish with three to eight strands is usually employed. The overall performance of a tundish is dominated by the melt flow within it. Melt flow control is particularly difficult in multi-strand tundishes. The shortest circuit flow, towards the strand nearest to the ladle shroud, carries not only higher temperature molten steel but also many inclusions existing in the steel towards the closest mould in a multi-strand tundish, whereas the strands further away from the ladle shroud receive cleaner and lower temperature molten steel. So

\footnotetext{
* Shu-guo Zheng

Male, born in 1979, Ph. D., Associate Professor. His research interests mainly focus on clean steel technology and solidification segregation in steel. His academic research has lead to the publication of more than 80 papers.

E-mail: zhengsg@smm.neu.edu.cn
}

Received: 2016-08-11; Accepted: 2016-09-29 the non-uniformities of steel cleanliness and output temperatures from strand to strand exist as a result of the poor similarity among the strands in a multi-strand tundish ${ }^{[1,2]}$. The strand dissimilarity can be reduced and controlled effectively by incorporating appropriate flow control devices within a given multi-strand tundish design ${ }^{[2,3]}$. Therefore, both the inclusion removal and the strand similarity need to be taken into account when modifying the melt flow in a multi-strand tundish.

To achieve the desired melt flow result, flow control devices need to be installed in the tundish. Flow control devices are generally dams, weirs, baffles, impact pads, turbulence inhibitors or some combination of these. The analysis for the residence time distribution (RTD) curve is one of the most important and effective approaches to study the melt flow in the tundish. Much work has been reported using a physical modeling approach or/and numerical investigation to study the melt flow through the RTD curves in a multi-strand tundish ${ }^{[2-15]}$. However, these studies were limited to those caster tundishes with 3 to 8 strands. Thus, very little information is available on the melt flow in a multi-strand caster tundish with more than 8 strands. Obviously, more strands in a multistrand caster tundish leads to a more serious strand dissimilarity. Therefore, the melt flow control in a multi- 
strand caster tundish with more than 8 strands is more difficult and needs to be further investigated. Moreover, in contrast to the wealth of data available for melt flow in a multi-strand tundish by physical modeling or/and mathematical modeling, plant trials on melt flow in a multi-strand tundish are relatively scarce.

In the present study, the influence of different flow control devices on the melt flow in a ten-strand billet caster tundish was investigated by physical modeling to find an optimal proposal. Fn thermore, the incls ion removal in the tnd sh $b$ fore and after the optimization was also studied by plant trials to evaluate the melt flow control in the tundish.

\section{Experimental procedure}

\subsection{Similarity considerations and experimental method}

A ten-strand billet caster tundish was selected as a prototype. During the practical continuous casting process, two symmetrical tundishes (with five strands each) receiving molten steel from one ladle by two ladle shrouds simultaneously, were used to distribute molten steel to ten moulds at the same time. Considering that the two tundishes are symmetrical, one of the two tundishes, with a capacity of 34 tonnes, was modeled and its physical dimensions are shown in Fig. 1. In a physical modeling system, water is a suitable liquid to replace liquid steel at $1,823 \mathrm{~K}$, because the kinematic viscosities of the two are comparable. To ensure the liquid flow similarity between the model and prototype, geometrical and dynamic similarities must be satisfied. In the present study, the ratio of geometrical similarity of model tundish to the prototype was chosen to be 1:2.5, and Fig. 2 shows the photograph of model tundish. In the system of a tundish, the physical model should have the same Froude number as the prototype ${ }^{[16-18]}$. Therefore, the relations of liquid flow rates between the model and prototype can be expressed as follows:

$$
Q_{\mathrm{m}}=\lambda^{\frac{5}{2}} Q_{\mathrm{p}}
$$

where $\lambda$ is the geometrical scale factor, $Q_{\mathrm{m}}$ and $Q_{\mathrm{p}}$ are the liquid flow rates of the model and the prototype, respectively.
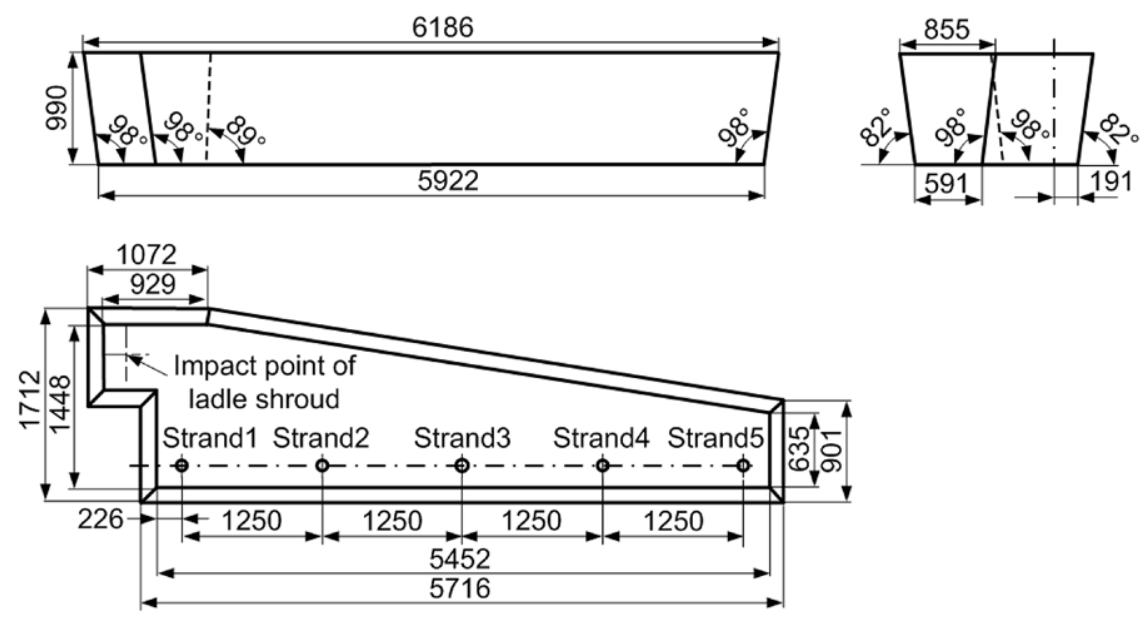

Fig. 1: Geometry dimensions of industrial tundish used in this study (mm)

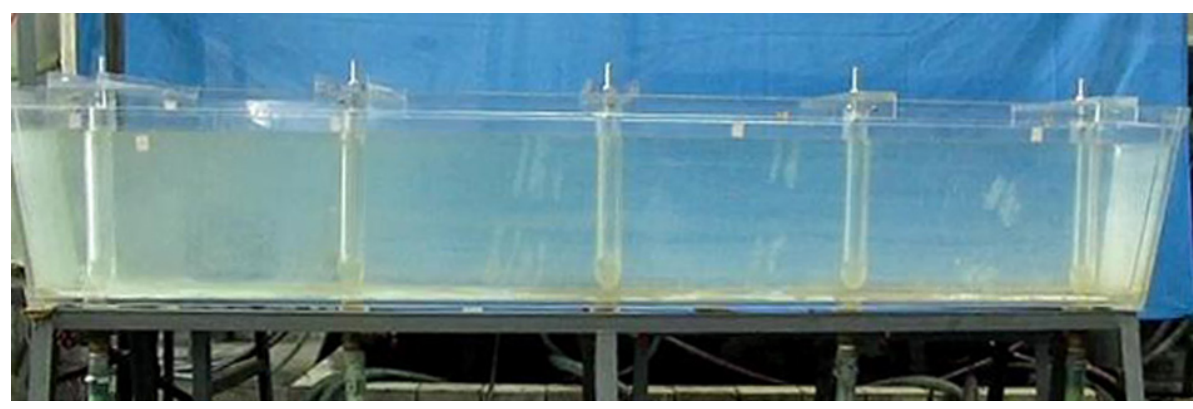

Fig. 2: Photograph of model tundish

To obtain the RTD curves, the stimulus response technique consisting of an instantaneous addition of tracer was employed. When a steady state flow condition was obtained in the model tundish, $200 \mathrm{ml}$ of a $20 \%$ sodium chloride solution, as a tracer, was injected into the water stream flowing through the ladle shroud. Meanwhile, five conductivity probes, which were connected to five conductivity meters, were installed below strands 1 to 5 of the tundish to measure the instantaneous concentration of the tracer as a function of time at each strand. The measurement data were input into a computer and then a group of RTD curves were obtained.

\subsection{Analysis of RTD curves}

By analyzing the RTD curve, the melt flow in a tundish can be characterized. Commonly, the melt flow in a tundish can be divided into the plug flow, mixed flow and dead volumes. 
In a multi-strand tundish, the accuracy of the melt flow characterization depends on the rationality of the analysis model for RTD curves. In our previous works ${ }^{[2,19]}$, an analysis model to characterize the melt flow in multi-strand tundishes has been proposed and its reasonability has also been verified. With this analysis model, the three volumes can be calculated as follows:

$$
\begin{gathered}
\frac{V_{\mathrm{p}}}{V}=\frac{1}{5} \cdot\left(\theta_{1 \mathrm{~min}}+\theta_{2 \mathrm{~min}}+\cdots+\theta_{5 \mathrm{~min}}\right) \\
\frac{V_{\mathrm{d}}}{V}=1-\frac{1}{5} \cdot\left(\frac{Q_{1 \mathrm{a}}}{Q_{1}} \cdot \bar{\theta}_{1 \mathrm{c}}+\frac{Q_{2 \mathrm{a}}}{Q_{2}} \cdot \bar{\theta}_{2 \mathrm{c}}+\cdots+\frac{Q_{5 \mathrm{a}}}{Q_{5}} \cdot \bar{\theta}_{5 \mathrm{c}}\right) \\
\frac{V_{\mathrm{m}}}{V}=1-\frac{V_{\mathrm{p}}}{V}-\frac{V_{\mathrm{d}}}{V}
\end{gathered}
$$

where $V_{\mathrm{p}} / V, V_{\mathrm{m}} / V$ and $V_{\mathrm{d}} / V$, are the fractions of plug flow, mixed flow, and dead volume respectively. $\theta_{i \min }$ is the dimensionless time of the first appearance of tracer at strand $i(i=1$ to 5$), \bar{\theta}_{i \mathrm{c}}$ is the dimensionless mean residence time of strand $i$ ( $i=1$ to 5), $Q_{i a}$ l $Q_{i}$ is the fractional flow rate through the active volume of strand $i$, which is numerically equal to the area under the dimensionless RTD curve (the plot of the dimensionless concentration $C$ against the dimensionless time $\theta$ ) of strand $i$ as $\theta$ from 0 to 2 , as shown in Fig. 3 ( $i=1$ to 5 ).

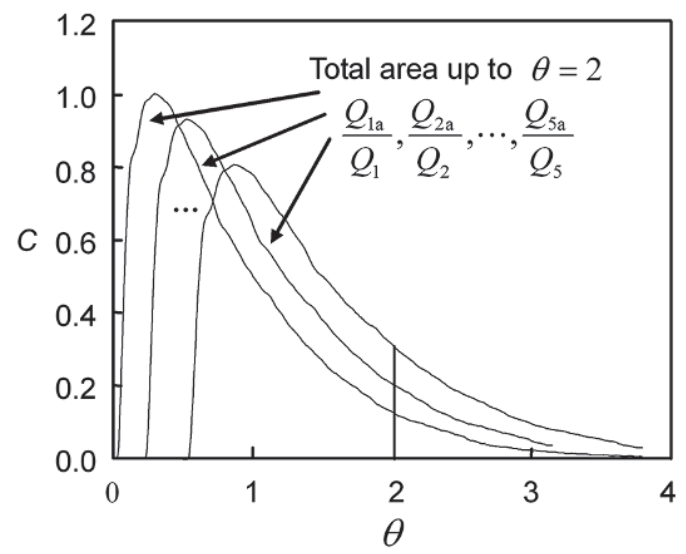

Fig. 3: Schematic of a group of typical RTD curves in a fivestrand tundish

As the similarity among the strands affects the uniformities of both steel cleanliness and output temperatures among the strands in multi-strand tundishes, besides those parameters related to the inclusion removal such as plug flow, mixed flow, and dead volumes, the strand similarity also needs to be considered when optimizing the melt flow in multi-strand tundishes. An approach for quantifying the strand similarity in multi-strand tundishes ${ }^{[2,20-21]}$ is used, i.e., all the standard deviations, those of dimensionless concentrations $\left(C_{i}\left(t_{j}\right), i=1\right.$ to $5, j=1$ to $Z$ ) of strands 1 to 5 at instantaneous time $t_{j}(j=1$ to $Z$ ), are averaged as follows:

$$
\bar{S}_{5}=\frac{1}{Z} \sum_{j=1}^{Z} \sqrt{\frac{\sum_{i=1}^{5}\left(C_{i}\left(t_{j}\right)-\bar{C}\left(t_{j}\right)\right)^{2}}{4}} \quad(i=1 \text { to } 5, j=1 \mathrm{t} \text { o } Z)
$$

where $\bar{S}_{5}$ is the total mean standard deviation of dimensionless concentrations of strands 1 to $5, t_{j}$ is the instantaneous time, $C_{i}\left(t_{j}\right)$ is the dimensionless concentration of strand $i$ at instantaneous time $t_{j}$, ( $i=1$ to $5, j=1$ to $\left.Z\right)$. $Z$ is the number of instantaneous time $t_{j}$. $\bar{C}\left(t_{j}\right)$ is the mean of the dimensionless concentrations of strands 1 to 5 at instantaneous time $t_{j}(j=1$ to $Z$ ). For better similarity among the strands, the lower total mean standard deviation $\bar{S}_{5}$ is desired.

\subsection{Various flow control arrangements}

Via a ladle shroud, the metal stream from the ladle enters into the tundish at a very high velocity and great turbulence. The impact of the stream at the tundish bottom may cause severe refractory erosion problems, so an impact pad or a turbulence inhibitor, placed at the bottom, is necessary to withstand the erosive force of the ladle stream. Moreover, in the multi-strand tundish, the appropriate baffle with inclined holes can avoid the short circuiting flow of the strand nearest to the ladle shroud ${ }^{[2]}$. As the effect of a turbulence inhibitor or an impact pad on flow control in the multi-strand tundish is weak in the area far from the impact zone (for example, in the present ten-strand caster tundish, strand 5 is $5,500 \mathrm{~mm}$ away from the ladle shroud), the combination of a turbulence inhibitor (or an impact pad) and a baffle with inclined holes, properly designed, may improve the melt flow efficiently. Therefore, for the present ten-strand caster tundish, the combination of a turbulence inhibitor (or an impact pad) and a baffle with inclined holes was adopted to optimize the melt flow. The typical flow control arrangements are shown in Fig. 4, and Fig. 5 shows the flow control devices. Baffles A to C are "V" type baffles, while baffles D and E are straight baffles. Case I is the original case in prototype. Cases I to IV had the same baffle (baffle A) but different flow control devices in the impact zone (an impact pad in Case I and turbulence inhibitors A to C in cases II to IV in turn). Combined with the same turbulence inhibitor (turbulence inhibitor C), baffles B to E were arranged in cases V to VIII in sequence.

\subsection{Optimization principles}

For the multi-strand tundish, both the inclusion removal and the strand similarity are of concern when optimizing the melt flow. Therefore, to gain the maximum inclusion separation ratio and the good strand similarity by installing flow control devices in a multi-strand tundish, it is necessary to ensure the following optimization principles ${ }^{[2,16,22]}$ :

(i) minimum dead volume;

(ii) large ratio of plug to dead volume;

(iii) surface-directed flow;

(iv) contained regions of mixing;

(v) minimum total mean standard deviation of the dimensionless concentrations of strands 1 to 5 ;

(vi) the most important principle in the cleanness of tundish product is ensuring there are no short circuit flows. The time for first appearance of tracer, particularly at the nearest strand, strand 1 , should be as long as possible. 

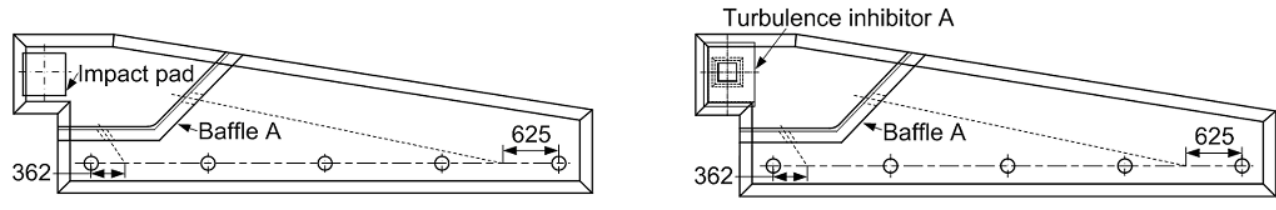

Case I

Case II
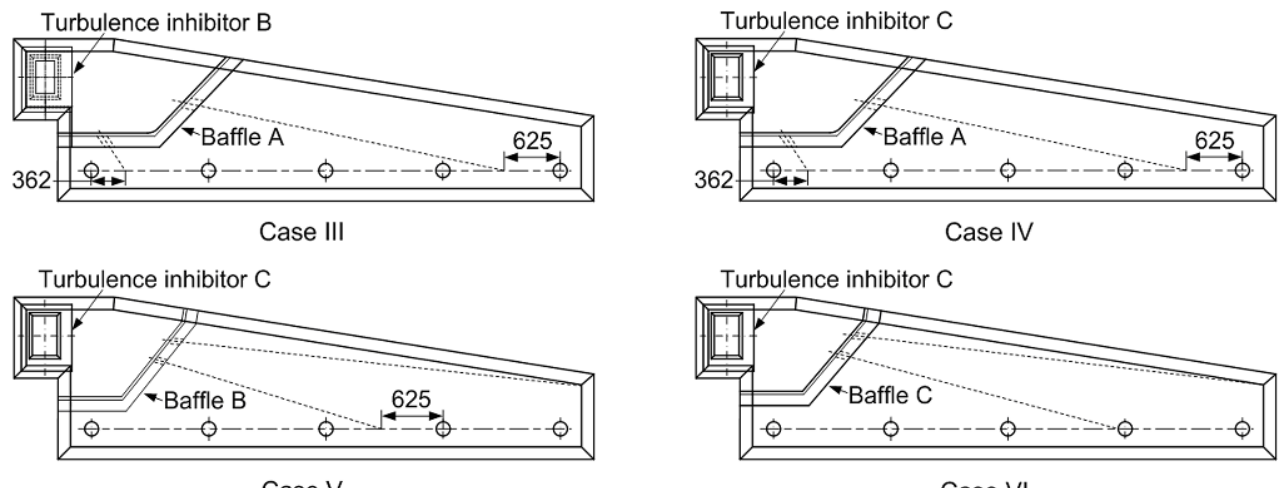

Case V

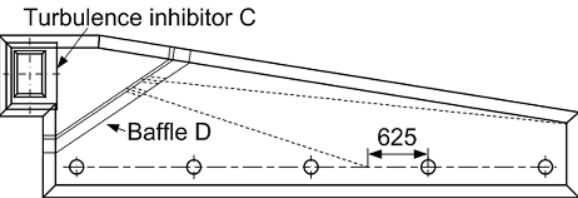

Case VII

Case VI

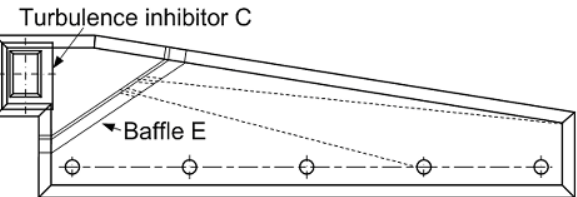

Case VIII

Fig. 4: Schematic of various flow control arrangements

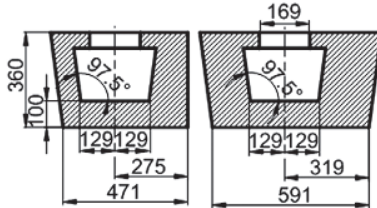

Turbulence inhibitor $A$

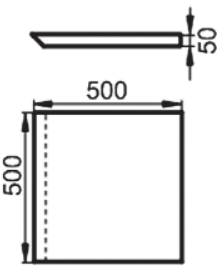

Impact pad



Baffle B $\left(\alpha=22.8^{\circ}\right)$ or $C\left(\alpha=25.8^{\circ}\right)$

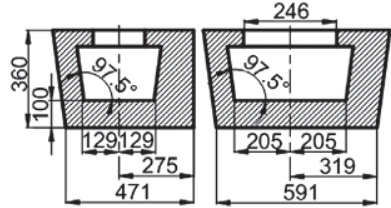

Turbulence inhibitor B
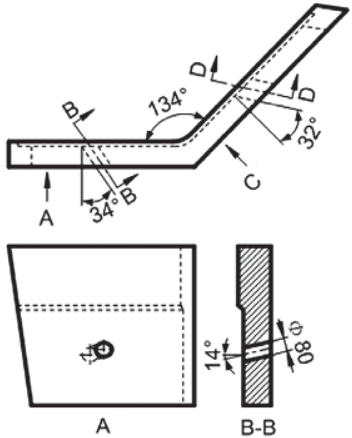

Baffle A

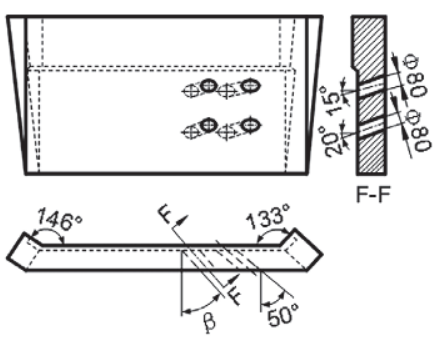

Baffle $D\left(\beta=39^{\circ}\right)$ or $E\left(\beta=42^{\circ}\right)$

Fig. 5: Geometry and dimensions of flow control devices ( $\mathrm{mm}$ ) 


\section{Results and discussion}

\subsection{Experimental results}

The flow characteristics for different tundish configurations are shown in Table 1, and Fig. 6 shows the typical RTD curves. Then, combined with the above-mentioned optimization principles, the following points can be observed:

(i) When combined with a baffle, the turbulence inhibitor instead of the impact pad can significantly increase the plug volume, improving the melt flow. The designs of the turbulence inhibitors (the leng $h$ of inner cavity of to $\mathbf{b}$ ence inhib tors, with or without extending lip at the top of the sidewall) all have an effect on the melt flow in the tundish. The turbulence inhibitor with a longer inner cavity length has a larger ratio of plug to dead volume, while the one with an extending lip at the top of the sidewall worsens the strand similarity. So, turbulence inhibitor $\mathrm{C}$ is the optimal one for controlling the melt flow among the three kinds of turbulence inhibitors. (ii) The "V" type baffle with four inclined holes at the sidewall away from the stopper rods (baffles B and C) is better in controlling the melt flow than the baffle with one inclined hole at each sidewall (baffle A). An inclined hole, arranged on the sidewall near the stopper rods, is so close to strands 1 and 2 that the time of the first appearance of tracer at strands 1 and 2 is very short. Therefore, the "V" type baffle with one inclined hole at each sidewall has smaller plug volume and ratio of plug to dead volume than the baffle with four inclined holes at the sidewall away from the stopper rods.

(iii) Though both baffle types have four inclined holes away from the stopper rods, the "V" type baffles, with larger plug volume and smaller dead volume, show a higher efficiency in improving the melt flow than the straight baffles. Furthermore, the appropriate design of the horizontal direction of two of the four inclined holes near the stopper rods can improve the melt flow in both types of baffles. Cases VI and VIII (with the two inclined holes near the stopper rods pointing to just above strand

Table 1: Flow characteristics for different tundish configurations

\begin{tabular}{|c|c|c|c|c|c|c|c|}
\hline Case & Strand & $S_{\text {inin }}$ & $V_{p} / V$ & $V_{m} / V$ & $V_{\mathrm{d}} / V$ & $V_{p} / V_{d}$ & $\bar{S}_{5}$ \\
\hline \multirow{5}{*}{ I } & 1 & 0.0419 & \multirow{5}{*}{0.0755} & \multirow{5}{*}{0.6947} & \multirow{5}{*}{0.2298} & \multirow{5}{*}{0.3285} & \multirow{5}{*}{0.0441} \\
\hline & 2 & 0.0375 & & & & & \\
\hline & 3 & 0.0591 & & & & & \\
\hline & 4 & 0.0722 & & & & & \\
\hline & 5 & 0.1666 & & & & & \\
\hline \multirow{5}{*}{ II } & 1 & 0.0435 & \multirow{5}{*}{0.0948} & \multirow{5}{*}{0.6790} & \multirow{5}{*}{0.2262} & \multirow{5}{*}{0.4191} & \multirow{5}{*}{0.0460} \\
\hline & 2 & 0.0570 & & & & & \\
\hline & 3 & 0.0721 & & & & & \\
\hline & 4 & 0.1096 & & & & & \\
\hline & 5 & 0.1917 & & & & & \\
\hline \multirow{5}{*}{ III } & 1 & 0.0358 & \multirow{5}{*}{0.0925} & \multirow{5}{*}{0.6905} & \multirow{5}{*}{0.2170} & \multirow{5}{*}{0.4263} & \multirow{5}{*}{0.0568} \\
\hline & 2 & 0.0451 & & & & & \\
\hline & 3 & 0.0728 & & & & & \\
\hline & 4 & 0.1037 & & & & & \\
\hline & 5 & 0.2052 & & & & & \\
\hline \multirow{5}{*}{ IV } & 1 & 0.0607 & \multirow{5}{*}{0.0997} & \multirow{5}{*}{0.6722} & \multirow{5}{*}{0.2281} & \multirow{5}{*}{0.4371} & \multirow{5}{*}{0.0422} \\
\hline & 2 & 0.0721 & & & & & \\
\hline & 3 & 0.0630 & & & & & \\
\hline & 4 & 0.1010 & & & & & \\
\hline & 5 & 0.2015 & & & & & \\
\hline \multirow{5}{*}{ V } & 1 & 0.2073 & & & & & \\
\hline & 2 & 0.1091 & & & & & \\
\hline & 3 & 0.0640 & 0.1291 & 0.6359 & 0.2350 & 0.5494 & 0.0577 \\
\hline & 4 & 0.1059 & & & & & \\
\hline & 5 & 0.1591 & & & & & \\
\hline & 1 & 0.1938 & & & & & \\
\hline & 2 & 0.1091 & & & & & \\
\hline VI & 3 & 0.0656 & 0.1450 & 0.6351 & 0.2199 & 0.6594 & 0.0491 \\
\hline & 4 & 0.1238 & & & & & \\
\hline & 5 & 0.2324 & & & & & \\
\hline & 1 & 0.1656 & & & & & \\
\hline & 2 & 0.1059 & & & & & \\
\hline VII & 3 & 0.0630 & 0.1213 & 0.6085 & 0.2702 & 0.4489 & 0.0511 \\
\hline & 4 & 0.1265 & & & & & \\
\hline & 5 & 0.1454 & & & & & \\
\hline & 1 & 0.1987 & & & & & \\
\hline & 2 & 0.0765 & & & & & \\
\hline VIII & 3 & 0.0598 & 0.1242 & 0.6178 & 0.2580 & 0.4814 & 0.0570 \\
\hline & 4 & 0.1064 & & & & & \\
\hline & 5 & 0.1796 & & & & & \\
\hline
\end{tabular}




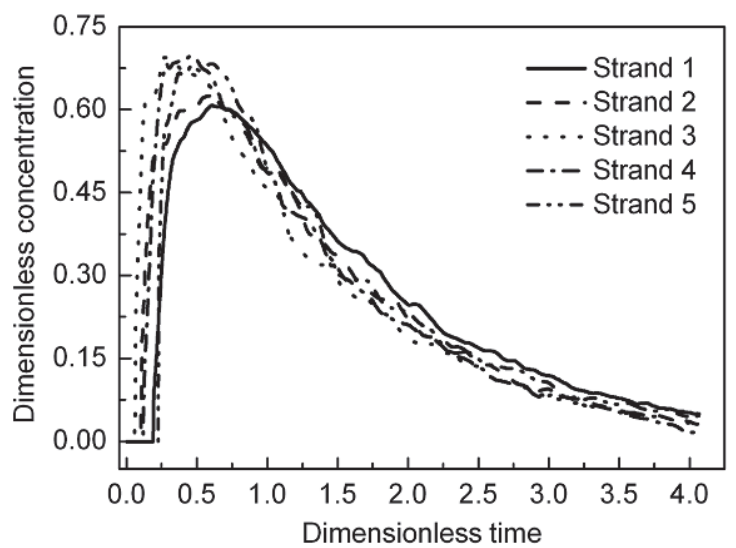

Fig. 6: RTD curves for Case VI

4) show better control on the melt flow in "V" type baffles (cases V and VI) and straight baffles (cases VII and VIII). Therefore, the baffles with two of the four inclined holes near the stopper rods pointing to just above Strand 4 show good control on the melt flow in the tundish. Furthermore, Baffle $\mathrm{C}$ is the best one for melt flow control among the five baffles.

(iv) The combination of a well-designed turbulence inhibitor and an appropriate baffle shows high efficiency on improving the melt flow in the ten-strand caster tundish. Compared with the other cases, Case VI (the combination of the optimal turbulence inhibitor and baffle) has the largest plug volume and ratio of plug to dead volume, and a relatively small dead volume and $\bar{S}_{5}$. (It can also be seen from Fig. 6 that the good uniformity among RTD curves of individual strands means the good strand similarity in Case VI.) On the whole, according to the optimization principles, it seems that Case VI is the best one for inclusion removal and strand similarity.

\subsection{Results of trial application}

To evaluate the effect of inclusion removal before and after the optimization of the melt flow in the ten-strand caster tundish, plant trials were conducted. The original case (Case I) in prototype and the optimal case (Case VI) were respectively installed in the two symmetrical tundishes during the production of high quality carbon structural steel 60 . In a casting sequence, billet samples with dimensions of $160 \mathrm{~mm} \times 160 \mathrm{~mm}$ were taken from the individual strand of the two symmetrical tundishes (one with Case I, the other with Case VI), and then $15 \mathrm{~mm} \times 15 \mathrm{~mm}$ samples were taken from the quarter thickness from the inner arc surface and center width positions of each billet sample. After the samples were mounted in bakelite and polished, a microscope was used to quantify the number and size of inclusions.

Figures 7 and 8 show the optical micrographs of inclusions in individual strands in original and optimal cases, respectively. The comparison of inclusion removal of each strand in the two cases is shown in Fig. 9. It can be seen that the inclusion number of each strand in the optimal case is much smaller (reduced by $42 \%$ ) than that in the original case. Furthermore, the inclusion distribution in the individual strands in the optimal case is more similar than that in the original case. Therefore, the optimal case is much better than the original case for the inclusion removal and the inclusion distribution similarity among the strands.

\section{Conclusions}

(1) When combined with a baffle, the turbulence inhibitor instead of the impact pad can significantly improve the melt flow in the ten-strand caster tundish. The designs of the turbulence inhibitors have an effect on the melt flow in the tundish; the turbulence inhibitor with longer inner cavity length and without extending lip at the top of the sidewall is better.

(2) Both the types and the designs of baffles influence the

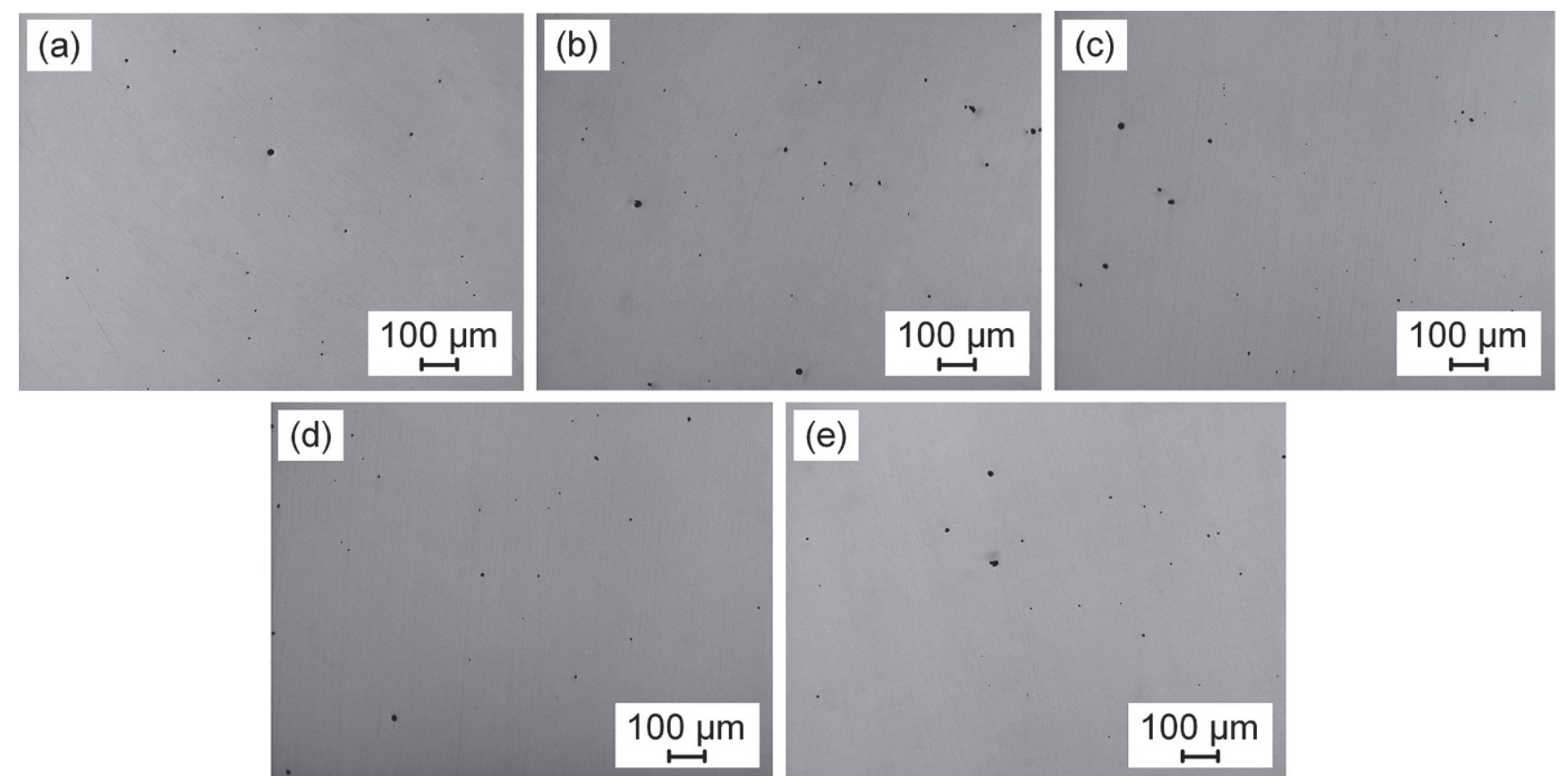

Fig. 7: Optical micrographs of inclusions in individual strands in original case: (a) Strand 1; (b) Strand 2; (c) Strand 3; (d) Strand 4; (e) Strand 5 

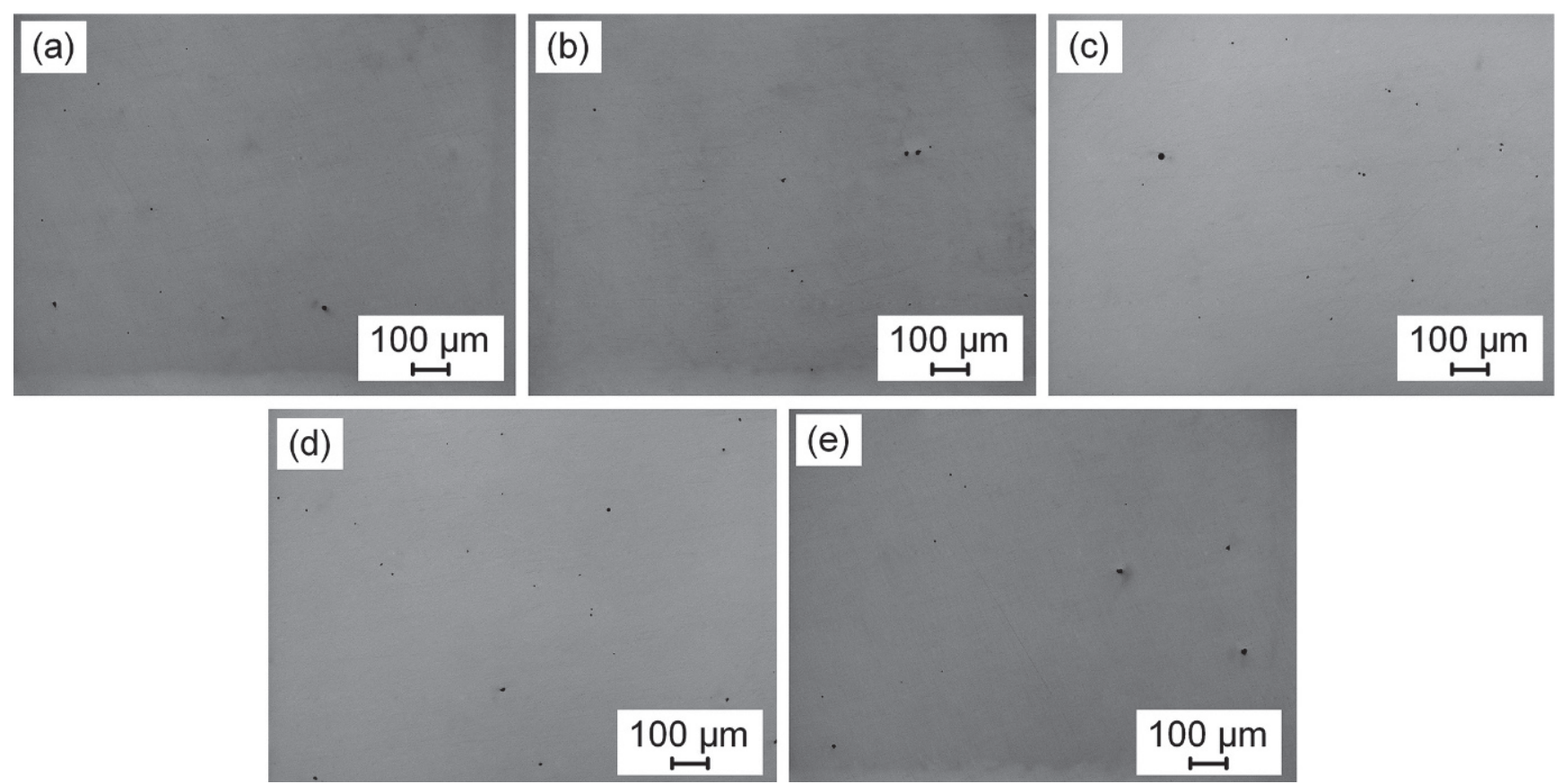

Fig. 8: Optical micrographs of inclusions in individual strands in optimal case: (a) Strand 1; (b) Strand 2; (c) Strand 3; (d) Strand 4; (e) Strand 5

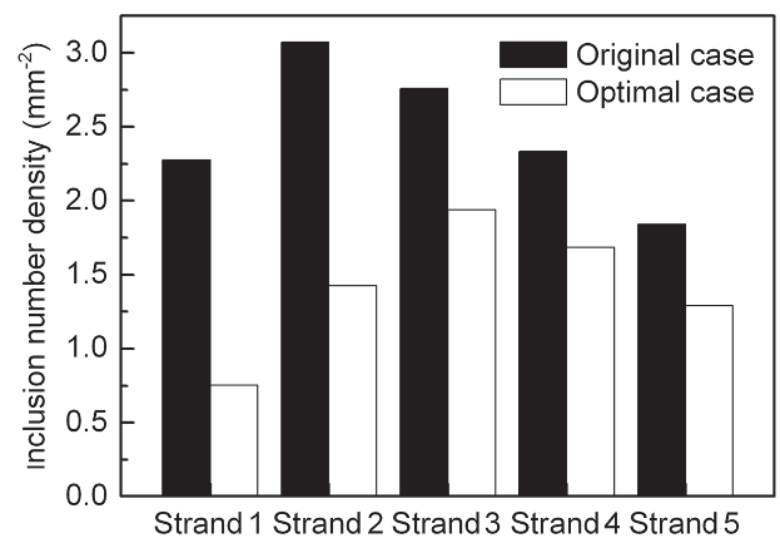

Fig. 9: Comparison of inclusion removal of each strand in original and optimal cases

flow characteristics significantly. The "V" type baffles show higher efficiency on improving the melt flow than the straight baffles. And the "V" type baffle with four inclined holes at the sidewall away from the stopper rods is better at controlling the melt flow than the one with one inclined hole at each sidewall. The baffles, with two of the four inclined holes near the stopper rods pointing to just above strand 4 , show good control on the melt flow in the tundish.

(3) The combination of a well-designed turbulence inhibitor and an appropriate baffle shows high efficiency in improving the melt flow in the ten-strand caster tundish. Case VI is the best for inclusion removal and strand similarity. The inclusion number is reduced by $42 \%$ and the inclusion distribution of individual strands is more similar after using the optimal combination.

\section{References}

[1] Fan C M, Pan S M, Wang H S, et al. Design of single element flow control device in twin strand billet tundish for continuous casting of steel using flow simulation model. Ironmaking and Steelmaking, 2002, 29(5): 376-382.

[2] Zheng Shuguo and Zhu Miaoyong. Optimization of baffles in six strands round bloom continuous casting tundish: a physical modeling study. Ironmaking and steelmaking, 2006, 33(5): 398-406.

[3] Mazumdar D, Yamanoglu G, and Guthrie R I L. Hydrodynamic performance of steelmaking tundish systems: A comparative study of three different tundish designs. Steel Research, 1997, 68(7): 293-300.

[4] He Fei, Zhang Ling-ying and Xu Qi-yan. Optimization of flow control devices for a T-type five-strand billet caster tundish: water modeling and numerical simulation. China Foundry, 2016, 13(3): 166-175.

[5] Wang Min, Zhang Chaojie and Li Rui. Uniformity evaluation and optimization of fluid flow characteristics in a seven-strand tundish. International Journal of Minerals, Metallurgy and Materials, 2016, 23(2): 137-145.

[6] Ray S K, Isac M, and Guthrie R I L. Modelling performance of four-strand, 12t, delta shaped continuous casting tundish fitted with different flow modifying arrangements for better steel quality. Ironmaking and Steelmaking, 2011, 38(3): 173-180.

[7] Chang Sheng, Zhong Liangcai, and Zou Zongshu. Simulation of flow and heat fields in a seven-strand tundish with gas curtain for molten steel continuous-casting. ISIJ International, 2015, 55(4): 837-844.

[8] Kumar A, Mazumdar D, and Koria S C. Modeling of fluid flow and residence time distribution in a four-strand tundish for enhancing inclusion removal. ISIJ International, 2008, 48(1): 38-47.

[9] Li Yihong, Bao Yanping, Zhao Lihua, et al. Effect of diversion hole on flow trajectory of steel in multi-strand tundish. Iron and Steel, 2014, 49(6): 37-42. (In Chinese) 
[10] Chattopadhyay K, Isac M, and Guthrie R I L. Effect of flow modifiers on liquid metal cleanliness in four-strand delta shaped billet caster tundish. Ironmaking and Steelmaking, 2012, 39(6): 454-462.

[11] Lei Hong. New insight into combined model and revised model for RTD curves in a multi-strand tundish. Metallurgical and Materials Transactions B, 2015, 46(6): 2408-2413.

[12] Mishra S K, Jha P K, Sharma S C, et al. Effect of blockage of outlet nozzle on fluid flow and heat transfer in continuously cast multistrand billet caster tundish. Canadian Metallurgical Quarterly, 2012, 51(2): 170-183.

[13] Sun Yanhui, Xiong Huihui, Wang Xiaosong, et al. Research on simulation of liquid steel flow in a ASF billet 8-strand continuous casting tundish. Steelmaking, 2012, 28(2): 60-64. (In Chinese)

[14] Jiang Jing, Li Jingshe, Wu Huajie, et al. Water modeling of molten steel flow in a multi-strand tundish with gas blowing. International Journal of Minerals, Metallurgy and Materials, 2010, 17(2): 143-148.

[15] Zhong Liangcai, Li Baokuan, Zhu Yingxiong, et al. Fluid flow in a four-strand bloom continuous casting tundish with different flow modifiers. ISIJ International, 2007, 47(1): 88-94.

[16] Sahai $Y$ and Ahuja R. Fluid flow and mixing of melt in steelmaking tundishes. Ironmaking and Steelmaking, 1986, 13(5): 241-247.

[17] Singh S and Koria S C. Physical modeling of steel flow in continuous casting tundish. Ironmaking and Steelmaking 1993 20(3): 221-230.

[18] Singh S and Koria S C. Model study of the dynamics of flow of steel melt in the tundish. ISIJ International, 1993, 33(12): 1228-1237.

[19] Zheng S G and Zhu M Y. Analysis model for flow characteristics in multi-strand continuous casting tundish. Acta Metallurgica Sinica, 2005, 41(10): 1073-1076. (In Chinese)

[20] Zheng S G and Zhu M Y. Criteria on the similarity of melt flow among strands in multi-strand continuous casting tundish. The Chinese Journal of Process Engineering, 2006, 6(4): 522-526. (In Chinese)

[21] Sengupta A, Mishra P, Singh V, et al. Physical modeling investigation of influence of strand blockage on RTD characteristics in a multistrand tundish. Ironmaking and Steelmaking, 2013, 40(3): 159-166.

[22] Mazumdar D and Guthrie R I L. The physical and mathematical modelling of continuous casting tundish systems. ISIJ International, 1999, 39(6): 524-547.

This work was supported by the National Natural Science Foundation of China (No. 51474059, No. 51204042), the Program for Liaoning Excellent Talents in University (No. LJQ2014031), and the Fundamental Research Funds for the Central Universities (No. N140205003). 